\title{
A Fragmentation Based Approach to the Free Form Surface Milling
}

\author{
Jozef Beňo ${ }^{1 *}$, Peter lžol ${ }^{2}$, Miroslav Tomáś ${ }^{2}$ and Ján Varga ${ }^{2}$ \\ 1 Faculty of Mechanical Engineering, Technical University of Košice, Department of Technology and Material, Košice, Slovakia \\ ${ }^{2}$ Faculty of Mechanical Engineering, Technical University of Košice, Department of Computer Suport of Technology, Košice, Slovakia
}

\begin{abstract}
In this paper, authors performs analysis of the free-form surface milling based on the fragmentation of the design elements which create active surfaces in tool making. Their analysis is based on fragmentation approach which makes the most of combining CAD, modelling and testing objects in tool making as well as selecting of the fragments with parts of free-form surfaces. Examples being introduced in this paper point out that it is volume based fragmentation of free form surfaces which allows to associate CAD design of tooling parts, their modelling and producing in chosen scale as well as testing different milling strategies. Results also showed that it is the Lining strategy of ball end milling which denotes desired compromise between machining time and surface quality when ball end milling fragments with different signed curvature radii.
\end{abstract}

Keywords: Tool making, tooling surface, design elements, fragmentation types, free form surface, signed curvature, roughness parameters.

\section{Introduction}

Tools for sheet forming and moulding have significant position in products innovation and reduction of their life cycle for determining product quality and accuracy. They include free-form elements and their active parts are produced by CNC milling which is the largest subject in this technology. State-of-the-art is very wide and can be categorised in six main fields listed hereinafter. The first field is surface design [1], [2] which employs basic features of free-form shape. Composition of the features allows generating complex surface being used in industry including tooling for sheet forming and plastic moulding. The second field is modelling and decomposition of free-form surfaces [3], [4] which applies division of product into fragments with parts of free-from surfaces. Fragments enable programming paths of ball end mill cutters which are based on orientation of any surfaces; such a methodology is applicable in design of moulds. The third field includes milling strategies and directions of tool path [5], [6] which consider machining time and dimension accuracy. Milling strategies assume elimination of the surface inaccuracy by means of topology data [7] and by tool edge contact with workpiece [8]. The fourth subject is programming of tool path and it represents topology and combining of tool motion and so-called CC points in tool path and $\mathrm{CL}$ points of cutter position [5]. To check surface inaccuracy, programming considers deformation of the cutter body [9]. The fifth field is performance of milling cutters as end mill and ball end mill, their performance is given by forces, tool body deformation and machined surface [10]. In moulding of plastics, combination of strategies, cutter diameter and way of milling do affect active surface [11]. Technology to produce sheet forming tools consists of division of active surfaces 
into fragments [12]. Finally, the last field is quality checking of active surface and critical spots of produced tooling. In fact that field combines following approaches: programming variable data as feed and spindle revolutions [13], surface texture simulation [14] and texture analysis in two directions [15]. To check true machined surface, 3D measurement of texture being dependent on feed and infeed is used [16]; however, digital analysis of texture due to various forms of contact between ball end mill cutter and work piece is applied [17]. In analysis of quality of free-form surfaces, such approaches as 3D metrology [5], roughness figures [13], [14], surface texture and Abbot's curves [16], texture variation in two directions [10] etc. are employed. Performance of end mill cutters is expressed in terms of tool edge wear [10], [11] and cutting forces [9], [13].

State-of-the art includes design of tooling, manufacturability and preparation of free-form surfaces. Design of tooling is based on product shape and CAD/CAM while its manufacturability determines types of cutter. Cited sources deal few with production of tooling in whole, they include but surface fragments. Manufacturability of freeform surfaces is determined with milling strategies, tool path programs, ways of milling and cutter diameters. Recommendations to use a milling strategy are very common, result of producing such surfaces is not easy predictable. Thus tooling with free-form elements needs finishing of active surfaces. Reduction of surface finishing can enable "preparation" of active surfaces for tooling which include form and relief elements. "Preparation of active surfaces", i.e. fields 4, 5 and 6 listed above, is given as relationship among tooling, process (deformation, friction, viscosity, etc.) and contact/ surface morphology being produced in free form milling, a sequence being explained in Figure 1.

Tooling for sheet forming and moulding make form product through their active parts. There are few figures about how any active surface and its morphology affect on process of material shaping into product. State-of-the art suggests, there is possible to create a morphology of active surfaces of tooling in such a way as they bear two marks. The first is morphology supporting process of shaping (sheet forming, moulding), the second mark is that CNC milling has to provide active surface requiring minimum of finishing or grinding. In order to reduce the need of finishing, process of free-from surface milling is proposed to study in terms of small fragment taken from real product and which are subsequently modelled in the different type of scale.

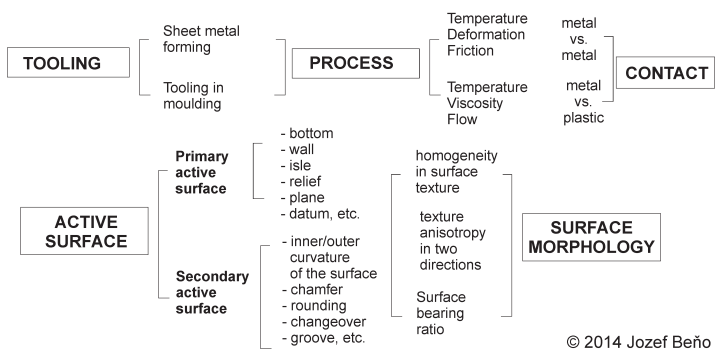

Fig. 1: An outline of the summary in state-of-the art: a chain expressing the sequence of the effects producing surface morphology when tool making.

\section{Rationale of the Tooling Fragmentation}

In contrast to the traditional milling operations, free-form milling produces 3D surfaces by means of programming and milling strategies. Thus, any surface can assume different features being expressed through measured quantity as its texture, tolerance and surface layer properties, as well. Because of programming, cutting conditions as feed per tooth $\mathrm{fz}$ [mm], depth of cut ap [mm] side step ae $[\mathrm{mm}]$ do vary, therefore, there is no possibility to express final quality of product in whole, but in its fragment. Figure 2 shows an example of tooling part produce by different combination of design elements. Basically, such a design element can bear its typical attribute and that are mainly such notations as changeover, transition, relief, rim and rounding. All the five attributes allow wide variety of the shapes for not expressing any dimension or a distance and that are chamfer, groove, wall, isle, etc., the design elements consisting of definite dimension. Finally, such common elements as plane and datum also allow to use not only different milling strategies, but they also are supposed to make a link among others design elements as e.g., plane - rim - wall, or as wall - bottom - relief, etc.

Manufacturing of the tooling shape in Figure 2, though, consists of different milling strategies which are expressed through programming instructions; therefore, checking of the final shape gives lack of measurability. In order to secure proper checking of the machined surface quality, there is only way 
of securing such measurability, the measurable fragments. Fragments are supposed to bear all the significant attributes in the free-form surface whereas they must be capable of identifying and measuring the active surface of tooling being expressed in Fig. 1. In order to achieve such a surface checking, the fragmentation is introduced to analyse the fragments of the whole relief surfaces.

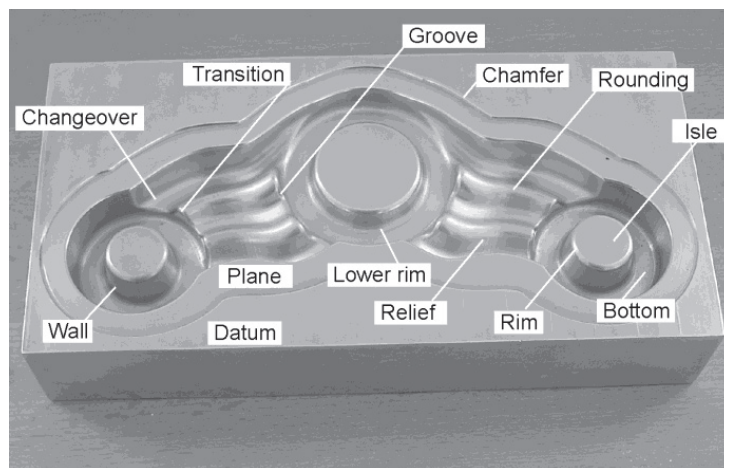

Fig. 2: (a) An example of design elements when tool making the lower die: a combining of the design attributes and design elements with definite dimensions.

\section{Tooling Fragmentation Varietes and Their Features}

Basic idea of free-form surface fragmentation is that a pattern is taken from the tooling entity, which can be further studied as a fragment of the surface or as a sample being produced in laboratory. This approach offers study of wide scale of effects as formulation of the surface as for instance, radii, their transition, datum in Figure 2 which replaces the parts of planes as bottoms, walls, etc. Because of wide varieties in fragmentation, three ways of expressing fragment shape are introduced below.

\subsection{CAD Based Fragmentation}

CAD based fragmentation of the free-form surface seems to be the feasible tool to investigate end ball milling process. Main advantage in such a way is that any part of the free form surface is transferred into virtual volume (mainly $100^{3} \mathrm{~mm}^{3}$ ) in Figure 3 wherein such analyses as modelling and simulation of machining are used. Thus, CAD drawing of tooling part thus allows to take out the representatives of free form surfaces. It means in fact that such samples allows to identify feasible milling strategy as well as to make out modelled surface finish. Such way of free form surface fragmenting makes the most of applying calculation of the scallop heigh, the surface error in Figure 4, however, roughness models in Figure 4 are based on sequence of milling operations in LINING Milling Strategy. In modelling of cusp height, roughing applies ball-end-mill cutter of diameter $\mathrm{D}=$ $16 \mathrm{~mm}$; semi finishing is modelled with $\mathrm{D}=10 \mathrm{~mm}$ and finishing results from $\mathrm{D}=6 \mathrm{~mm}$.
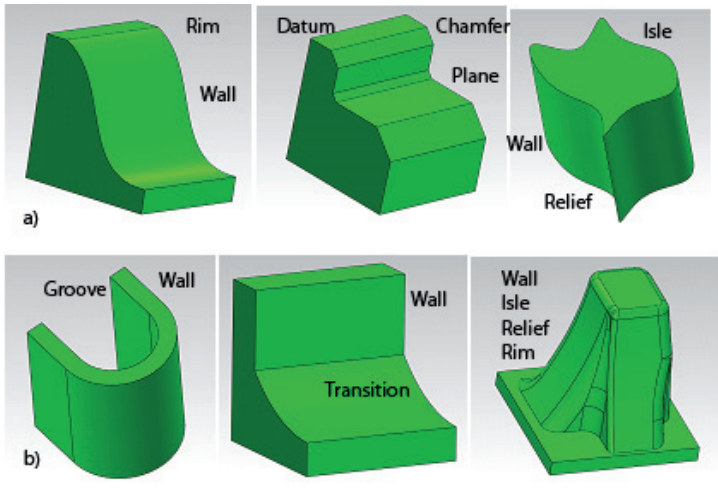

Fig. 3: CAD based fragmentation: attributes of the free form surface in tool making (a) Fragments based on measurability (b) Fragments based on combining of dimension.
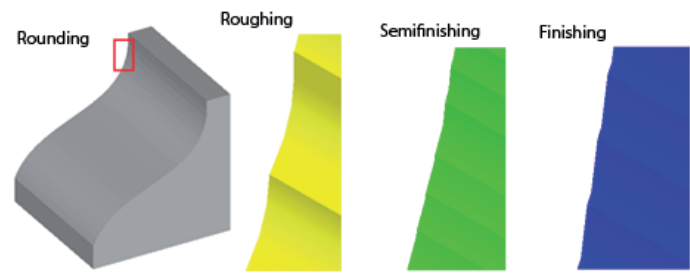

Fig. 4: CAD based fragmentation and sequence of producing resultant surface finish a case of the LINING strategy.

\subsection{Object Based Fragmentation}

While CAD based fragmentation allows to identify wide variety of milling strategies and their effect on surface finish, results always need verifying. In principle, object based fragmentation represents the art of selecting an object which is included in the design of tooling and subsequently such an object is modelled in terms of different milling strategies. Simple parabolic surface $y=30-0.048 x^{2}$ was used to verify this approach whereas three kinds of milling strategy as SPIRAL, CONSTANT $Z$ LEVEL and LINING were used to produce resultant surface finish. Commercial sintered carbide ball 
end milling cutter $\mathrm{D}=8 \mathrm{~mm}$ was used to machine AlCu4Mg alloy (feed per tooth $f_{z}=0.03 \mathrm{~mm}$, revolutions $\mathrm{n}=4900 \mathrm{1} / \mathrm{min}$, side step $\mathrm{ae}_{\mathrm{e}}=0,5 \mathrm{~mm}$, coolant: emulsion, machine tool EMCOMILL 155 with control unit Heidenhein TNC 426). Figure 5 illustrates an example of comparing CAD model with real machined object and data in Table 1, the parameters of surface roughness by ISO 4287, make distinguish suitability the Constant Z level as the strategy reducing subsequent grinding and polishing of this part of tooling, an isle/wall/ transition according to the notation shown in Figure 2.

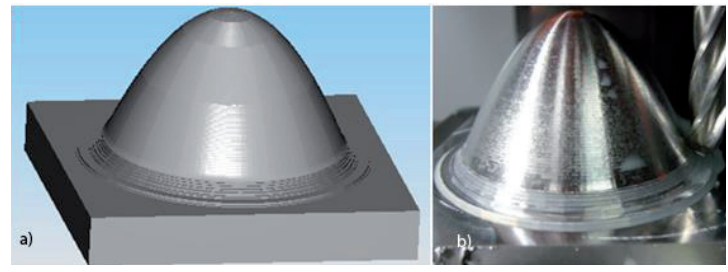

Fig. 5: An example of object based fragmentation: (a) CAD representation of the object defined by parabolic equation; (b) applying of the Spiral Milling Strategy to produce resultant surface finish.

Table 1: Results of measuring surface texture parameters when ball end milling (Mitutoyo SJ 301)

\begin{tabular}{|c|c|c|c|c|c|}
\hline Milling strategy & $\begin{array}{l}\mathrm{Ra} \\
\text { [pm] }\end{array}$ & $\begin{array}{l}\text { Rzz } \\
\text { [pm] }\end{array}$ & $\begin{array}{l}\text { Rt } \\
{[\mu \mathrm{m}]}\end{array}$ & $\begin{array}{l}\text { Rp } \\
\text { [pm] }\end{array}$ & $\begin{array}{l}\text { Rv } \\
\text { [pm] }\end{array}$ \\
\hline SPIRAL & 2,19 & 9,78 & 11,71 & 5,74 & 3,96 \\
\hline CONSTANT Z LEVEL & 0,58 & 3,06 & 4,18 & 1,6 & 1,46 \\
\hline LINING & 1,69 & 8,01 & 10,83 & 4,5 & 3,51 \\
\hline
\end{tabular}

\subsection{Volume Based Fragmentation}

Two main dimensions create the idea of the Volume Based Fragmentation. The first dimension is $100^{3} \mathrm{~mm}^{3}$, a volume of a part of the product, either a part of tooling in fact as e.g., a any die, or an entity as e.g., tooling in injection moulding. A volumetric segment, which is supposed to be of $10^{3} \mathrm{~mm}^{3}$, represent a fragment to measure machined surface roughness, such a dimension allows to replace a part of relief surface by a circle. In order to measure any surface roughness parameter in uniform way, two circumstances must be considered, the measurability and signed curvature radius, the former means explicit positioning of the sample. The latter must be considered in evaluation of the results for true relief surface bears the changes of their radii and that is signed curvature radius. a fact is must be considered in the measured data evaluation. Such two circumstances are shown in Figure 6 whereas measurability results from positioning of fragment/sample at prismatic part known as Vee block.

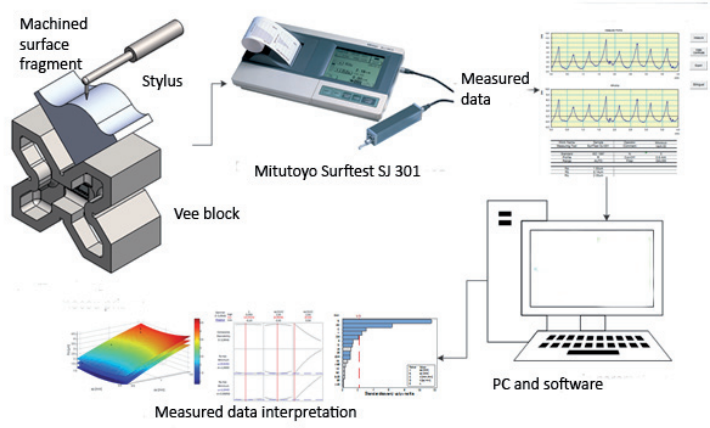

Fig. 6: Measurability of the surface roughness in Volume Based Fragmentation: a chain explains positioning of the fragment/sample of relief surface as well as processing of measured data.

Positioning of the machined surface in Vee block in Figure 7a) shows that stylus moves along ridge lines and valley lines of the machined surface while the former means position of stylus in that of Figure. If centre of a radius $R$, which defines a part of relief surface is located within a sample, it represents positive signed curvature radius which is taken as $k=1 / R$, a convex case of the signed curvature. Otherwise, the ratio $k=-1 /$ R represents the negative signed curvature, a concave case of the measured fragment: in other words said, the centre of the circle radius is located outside machined surface. Such cases of the signed curvature radii are shown in Figure 7(b) and their combination produces final fragment of the machined surface. Now, different milling strategies are applicable to such a fragment, the whole Figure 7 gives evidence about how milling strategy LINING is being investigated.

Experimental measurement were performed to identify effect of signed curvature $k$ and cutting conditions on surface roughness parameters $R a$ and Rz. Commercial sintered carbide ball end milling cutter $D=8 \mathrm{~mm}$ with number of flutes $z=2$ and helix angle 30 degree was used to machine AlCu4Mg alloy. The samples included radii and signed curvatures according to the Figure $7(b)$ while L27 Taguchi design was used in experiments. Identical range of depth of cut ap and side step ae $\left(a_{p}=0.5-1.5 \mathrm{~mm}, a_{e}=0.5-1.5 \mathrm{~mm}\right)$ were used in L27 Taguchi design while feed rate and spindle 


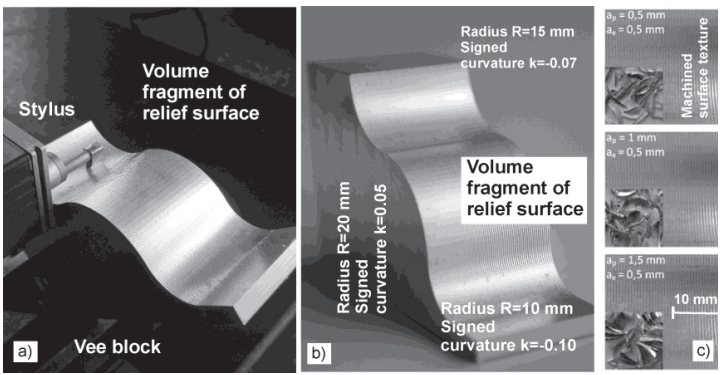

Fig. 7: Measurability of the relief surface fragment: (a) positioning of the fragment at the Vee block and different curvature radii measured in uniform way (b) volume fragment and related radii used in experimental measurements (c) surface texture and its changes as an effect of the depth of cut ap (milling strategy LINING, signed curvature $k=-0.10 \mathrm{~mm}$, roughness range $R a=1.30-1.60 \mu \mathrm{m}$ ).

revolutions were $\mathrm{V} f_{\mathrm{f}}=1500 \mathrm{~mm} / \mathrm{min}$ and $\mathrm{n}=5000$ 1/min; machine tool EMCOMILL 155 with control unit Heidenhein TNC 426. The L27 design was created by means of MiniTAB software and there is no need to explain its matrix here for returning evaluation instantly including relevance of results. The roughness parameters $R a$ and $R z$ were measured at the ridge/valley lines shown in Figure 7(a) and Taguchi L27 returned following statistical formulae:

$$
\begin{aligned}
& R a=0.58+k-1.71 \mathrm{a}_{\mathrm{p}}+3.63 \mathrm{a}_{\mathrm{e}}+12 k^{2}+1.09 \mathrm{a}_{\mathrm{p}}^{2} \\
& -0.50 \mathrm{a}_{\mathrm{e}}^{2}+0.97 k \cdot \mathrm{a}_{\mathrm{p}}-1.69 k \cdot \mathrm{a}_{\mathrm{e}}-0.40 \mathrm{a}_{\mathrm{p}} \cdot \mathrm{a}_{\mathrm{e}} \\
& R z=0.33+2.10 k-8.23 \mathrm{a}_{\mathrm{p}}+22.7 \mathrm{a}_{\mathrm{e}}+102 k^{2} \\
& +4.43 \mathrm{a}_{\mathrm{p}}^{2}-5.50 \mathrm{a}_{\mathrm{e}}^{2}+6.97 k \cdot \mathrm{a}_{\mathrm{p}}-7.60 k \cdot \mathrm{a}_{\mathrm{e}} \\
& -0.57 \mathrm{a}_{\mathrm{p}} \cdot \mathrm{a}_{\mathrm{e}}
\end{aligned}
$$

Meaning of the above mentioned formulae is contribution of the ball end milling factors to the resultant surface roughness. Though determination index is very high $\left(R^{2}=0.94\right.$ and 0.91 , respectively), contribution of the factors as ae and $a_{e}$ and $k$ is quite different. Results of ANOVA (Analysis of variance) points out that the ae bears the main effect on the resultant surface roughness which was found out to be about 90 - 91 percent, while the $a_{p}$ and $k$ brought effects no greater than 2.1 - 2.5 percent. In other words said, the signed curvature of workpiece is rendered through the errors in models, thus final effect of ae and ap was found out as:

$$
\begin{aligned}
& R a=0.62-1.75 \mathrm{a}_{\mathrm{p}}+3.71 \mathrm{a}_{\mathrm{e}}+1.02 \mathrm{a}_{\mathrm{p}}^{2}-0.50 \mathrm{a}_{\mathrm{e}}^{2} \\
& -0.40 \mathrm{a}_{\mathrm{p}} \cdot \mathrm{a}_{\mathrm{e}} \\
& R z=0.27-8.51 \mathrm{a}_{\mathrm{p}}+23.00 \mathrm{a}_{\mathrm{e}}+4.43 \mathrm{a}_{\mathrm{p}}^{2}-5.61 \mathrm{a}_{\mathrm{e}}^{2} \\
& -0.57 \mathrm{a}_{\mathrm{p}} \cdot \mathrm{a}_{\mathrm{e}}
\end{aligned}
$$

and they are shown in Figures 8(a) and (b).

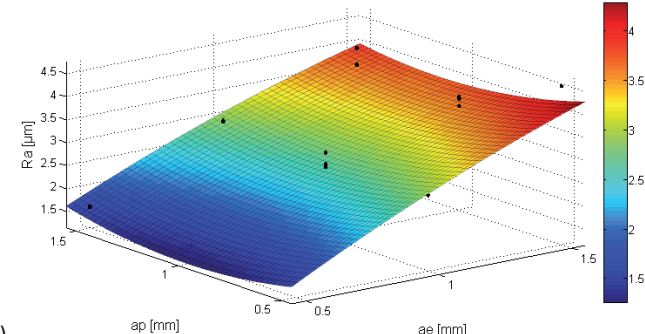

a) ap [mाா]

ae $[\mathrm{mm}]$

b)

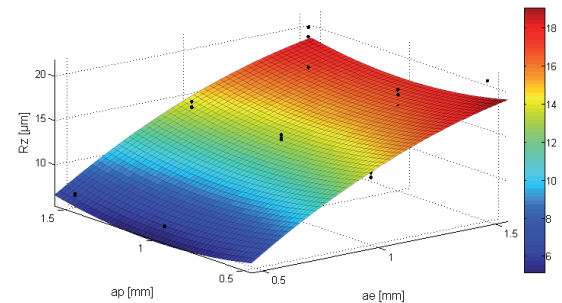

Fig. 8: Effect of cutting conditions ap and ae on surface roughness parameters based on L27 Taguchi design (a) mean arithmetic deviation $R a(b)$ average maximum height of the profile $R z$.

\section{Results and Discussion}

Free form machining turns out to be a base of the advanced technology to manufacture innovative products, thus many attention is paid to machining plans while operations of finishing ball end milling are supposed to reduce subsequent grinding and polishing of the moulds. Division of product into fragments, however, proves that each part of product is machined under different set of circumstances (milling strategy, cutting conditions, tool diameter, motion of ball end mill cutter as downward or upward, etc.), therefore, CAD based approach represents nothing but an approximate solution for not including such a set of circumstance in whole. CAD based fragmentation is applicable in limited scale for such surfaces as datum or inclined walls. The former, however, implies such a shape of fragment to provide for measurability. Figure 3(a) indicates such a case of fragmentation whereat desired measurability is provided for. 
An advantage of such a case of fragmentation is that it is capable of displaying machined surface, though this displaying of machined surface does not distinguish elements in set of circumstances mentioned above, for instance, Figure 4 says nothing about how such a texture is produced, or about how such a representation is applicable for different geometry/micro geometry of ball end milling cutter.

Object based fragmentation enables to check suitability of any milling strategy and Figure 5 shows a comparison of CAD modelling and real object. If the best result is desired, the Constant $Z$ level strategy seems to meet this requirement, however, total machining time is a limitation in this approach. Another limitation is measurability: the case of definition of the free-form surface allows to measure roughness parameters in only position. The last case in fragmentation approach is volume based approach shown in Figures 6 and 7. It allows to evaluate such a strategy of milling wherein the acceptable results are expected and measurability of roughness parameters is accomplished. Performed laboratory testing proves that it is side step ae in Lining Strategy which creates resultant roughness $R a$ and $R z$. The ways of volume based approach can be found in some works which test either milling strategies or they investigate effect of cutting conditions on machined surface parameters. However, such works investigate mainly milling of hardened steed for tool making purpose as [10] which quotes what is Lining strategy and $R a=$ $0.3-1.8 \mu \mathrm{m}$ in initial stage of tool wear when $\mathrm{a}_{\mathrm{e}}=$ $1 \mathrm{~mm}$ and $a_{\mathrm{p}}=0.5 \mathrm{~mm}$. In uniformly spaced lining strategy, the source [13] quotes $R a=1.49 \mu \mathrm{m}$ and $R z=5.61 \mu \mathrm{m}$ when machining aluminium 6061T6. The source [11] introduces a sample which can be referred to Volume-based fragmentation to machine 1.2344 hardened steel and it allows investigation of way of milling (conventional/climb milling) and variable position of roughness measurement. Source [11] also shows that it is radial depth of cut alias ae which produces the $R a=0.25$ $-1.52 \mu \mathrm{m}$.

\section{Conclusion and Prospect}

In this paper, author introduce their results based on fragmentation of definite free-form surface in tool making. Their approach combines set of factors affecting design in tooling whereas simple notation of design shapes in tool making is introduced. Three ways of fragmenting active surfaces in tool making are proposed. There is limited field of application for CAD based fragmentation, it can be used to rapid creating of the fragments. Prospect of such an approach is that it will combine such quantities as models of surface fragment and their relationship to the kinematics of any milling strategy. The Object Based Approach represents definite part of tooling which can be produced in any scale to study effect of milling strategy on its resultant surface quality. It must be noted that roughness parameters are not only results assessing quality of free form milling, it is also dimension accuracy which implies surface metrology. Main advantage of the Volume Based Fragmentation is combining of $C A D$, experiments and surface metrology, thus, it provides for verifiable results being tested in laboratory. The variable signed curvature and design of testing piece presented in this paper are one of the possible solutions which are offered by design of tooling. Because of large set of factors as art of milling strategy, diameter of end ball milling cutter and its geometry, tooling fragment designed as 2D or 3D, cutting conditions, etc., use of experimental design identifies all the relevant influences and in fact, design of experiment allow to optimize this process as such.

\section{Acknowledgments}

This work was supported by the project VEGA 1/0360/15 Research on Active Surface Preparation For Advanced Tooling Produced by CNC Form Milling and VEGA 1/0434/15 Research on Process Dependent Interface when Milling with Small Diameter of End Mill Cutters granted by Scientific grant agency VEGA of Ministry of Education, Science, Research and Sport. Authors express also their thanks Slovak Research and Development Agency under Contract No. D07RP-0014-09.

\section{References}

[1] van den Berg, E., et al. Free form feature modelling: concepts and prospects. Computers in Industry. 49, 2012, 217-233.

[2] Pernot J.P. et al.: Incorporating free-form features in aesthetic and engineering product design: State-of-the-art report. Computers in Industry 59 (2008) 626-637.

[3] Radzevich S.: Conditions of proper sculpture surface machining. Computer Aided Design, 34, 2002, 707-740.

[4] Quinn J.A. et al.: Generalized Anisotropic Stratified Surface Sampling. IEEE Transactions on Vizualization and Computer Graphics, 10, 2012, No. 10, 1-16. 
[5] Lasemi A. et al.: Recent development in CNC machining of freeform surfaces: A state-of-the-art review. ComputerAided Design 42 (2010) 641 - 654.

[6] Quinsat Y., Laurent S.: Optimal selection of machining direction for three-axis milling of sculptured parts Int J Adv Manuf Technolology, (2006), DOI 10.1007/s00170-0060515-5.

[7] Schützer, K. et al.: Using Advanced CAM-Systems for Optimized HSC-Machining of Complex Free Form Surfaces. Journal of the Brazil Society of Mechanical Science. \& Engineering. 2007, Vol. 29, No. 3, 313-318.

[8] Toh C.K.: A study of the effects of cutter path strategies and orientations in milling. Journal of Materials Processing Technology 152 (2004) 346-356.

[9] Lopez de Lacalle L.N, Lamikiz A, Sanchez J.A, Salgado M.A. Toolpath selection based on the minimum deflection cutting forces in the programming of complex surfaces milling. International Journal of Machine Tools and Manufacture 2007:47(2):388 400

[10] Urbanski J.P. et al.: High speed machining of moulds and dies for net shape manufacture. Materials and Design 21, 2000, 395-402.

[11] Vivancos J. et al.: Optimal machining parameters selection in high speed milling of hardened steels for injection moulds. Journal of Materials Processing Technology 155156 (2004) 1505-1512.

[12] Sun G. et al.: Operation decomposition for freeform surface features in process planning. Computer-Aided Design 33 (2001) $621-636$.

[13] Vijayaraghavan A. et al.: Improving end milling surface finish by workpiece rotation and adaptive tool path spacing. International Journal of Machine Tools \& Manufacture 49 (2009) 89-98.

[14] Ning Liu er al.: Surface finish visualisation in high speed, ball nose milling applications. International Journal of Machine Tools \& Manufacture 45 (2005) 1152-1161.

[15] Ramos A.M. et al.: The influence of finishing milling strategies on texture, roughness and dimensio.nal deviations on the machining of complex surfaces. Journal of Materials Processing Technology 136 (2003) 209-216

[16] Denkena B. et al.: Kinematic and Stochastic Surface Topography of Machined, TiAl6V4-Parts by means of Ball Nose End Milling. Procedia Engineering 19 (2011) 81 - 87.

[17] Weinert K. et al.: Simulation of Surface-Microstructures Resulting from Milling Processes. In: International Conference on Smart Machining Systems, National Institute of Standards and Technology (NIST) Files, 2007, Gaithersburg, Maryland, USA.

\section{Biographical notes}

Jozef Beňo, MSc., PhD, (born in 1952) is senior lecturer at Faculty of Mechanical Engineering, Technical University Košice. He obtained his degree as Candidatus Scientiae in 1984, he works since 1994 as senior lecturer at Dept of Technology and Material. His working area covers such fields as basic principles of machining, machining technology innovations and their fundamentals. He is leading author of three textbooks devoted to the fundamentals of metal removal process. His achievements were published in such journals as Measurement, Journal of Material Processing Technology, Applied Surface Science, Procedia Engineering, all imprints of Elsevier. He is member of Editorial Board to two journal as Archives of Mechanical Technology and Gépgyártás/Journal of Machine Manufacturing.

Peter Ižol, MSc., PhD., (born in 1962) is fellow at the Technical University of Košice, Faculty of Mechanical Engineering, Dept of Computer Support of Technology. Graduated in 1986 at the VŠT Košice and obtained the PhD. degree (2005) in 23-07-9 Mechanical Engineering Technology and Materials at the Technical University of Košice. He is specialized in programming of numerical controlled systems of machining, especially to the machining strategies application, numerical simulation of cutting processes, tool wear and its reliability at cutting. He is an author/co-author of five textbooks, his five papers were registered in Web of Science and SCOPUS.

Miroslav Tomáš, Ing., PhD., (born in 1973) is fellow at the Technical University of Košice, Faculty of Mechanical Engineering, Dept of Computer Support of Technology. He graduated in 1996 at the Technical University of Košice in 23-07-8 Mechanical Engineering Technology. He obtained PhD. degree in 2001 in research of multi-operation deep drawing process at the Technical University of Košice. His research activities are aimed to material formability tests, testing methods to determine forming limits, numerical simulation of forming and die design in CAD/CAM systems and 3D modelling. He is an author/co-author of two textbooks, one his paper was registered in Current Contents paper, four papers were registered in Web of Science and SCOPUS.

Ján Varga, MSc., PhD, (born in 1983) is researcher at Dept of Computer Support of Technology. He achieved his PhD at Faculty of Mechanical Engineering, Technical University Košice in 2010. His working areas are processing and simulation of injection moulding, analysis of the mechanical properties of polymer materials as well as programming CNC machine tools for application of control units Heidenhain TNC 426, TNC 530 and SolidCAM. His most relevant achievements are published in Advances in Science and Technology in Poland. 